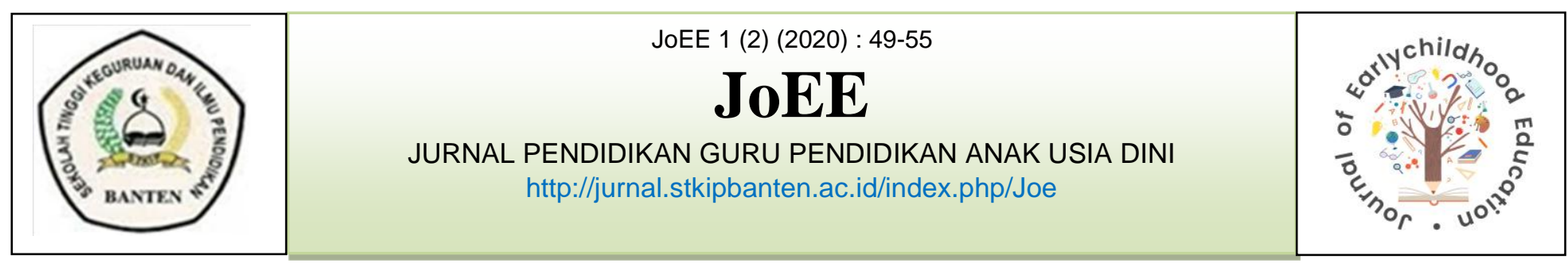

\title{
STUDI LITERATUR TENTANG KREATIVITAS ANAK DALAM PEMBELAJARAN SENI TARI JAIPONG MELALUI STRATEGI BELAJAR SAMBIL BERMAIN
}

\author{
Tubagus Rahman \\ tubagusrahman87@gmail.com \\ Pendidikan Guru Pendidikan Anak Usia Dini \\ Sekolah Tinggi Keguruan dan Ilmu Pendidikan Banten
}

\begin{abstract}
Abstrak
Kreativitas anak adalah sebagai kemampuan yang mencerminkan suatu gagasan sedangkan Seni tari Jaipong adalah seni tari yang berasal dari Jawa Barat yang yang menggerakkan seluruh anggota tubuh dengan bentuk yang indah. Tujuan penelitian ini adalah untuk mengetahui untuk mengetahui cara meningkatkan kreativitas anak usia dini melalui pembelajaran seni tari jaipong dengan strategi belajar sambil bermain. Metodologi penelitan ini menggunakan metode kualitatif dan jenis penelitiannya yaitu penelitian Studi Literatur. Hasil dari pembahasan adanya pengaruh kelenturan tubuh dan gerak tubuh dalam seni tari jaipong melalui strategi belajar sambil bermain, tanpa kelenturan atau keluwesan tubuh tidak akan sempurna seni tari jaipong karena saling berhubungan antara kelenturan tubuh dan seni tari. Sehingga dapat ditarik kesimpulan bahwa adanya peningkatkan kreativitas anak usia dini melalui pembelajaran seni tari dengan strategi belajar sambil bermain pada anak usia dini dengan gerak motorik baik gerak motorik kasar maupun gerak motorik halus.
\end{abstract}

Kata Kunci : Kreativitas Anak, Pembelajaran Seni Tari Jaipong

\section{PENDAHULUAN}

Pendidikan Anak Usia Dini (PAUD) pada hakikatnya ialah pendidikan yang diselenggarakan dengan tujuan untuk menfasilitasi pertumbuhan dan perkembangan anak secara menyeluruh atau menekankan pada pengembangan seluruh aspek kepribadian anak. Oleh karena itu Pendidikan Anak Usia Dini (PAUD) memberikan kesempatan kepada anak untuk mengembangkan kepribadian dan potensi secara maksimal. Kosekuensinya, lembaga Pendidikan Anak
Usia Dini (PAUD) perlu menyediakan berbagai aspek perkembangan (Suyadidan Maulidya Ulfah, 2015) .

Sebagaimana disebutkan dalam Undang-Undang Sistem Pendidikan Nasional No. 20 Tahun 2003 pada pasal 1 ayat (14) dinyatakan bahwa: "Pendidikan anak usia dini adalah suatu upaya pembinaan yang ditujukan kepada anak sejak lahir sampai dengan usia enam tahun yang dilakukan melalui pemberian 
rangsangan pendidikan untuk membantu pertumbuhan dan perkembangan jasmani dan rohani agar anak memiliki kesiapan dalam memasuki pendidikan lebih lanjut".

Kreativitas adalah suatu aktivitas imajinatif yang memanisfestasikan kecerdikan dari pikiran yang berdaya untuk menghasilkan suatu produk dan atau menyelesaikan suatu persoalan ${ }^{1}$. Salah satu kegiatan yang dapat dikembangkan di Taman Kanak-Kanak adalah kegiatan seni seperti seni tari. Seni tari dapat disesuaikan dengan perkembangan anak RA, karena aktivitas bergerak pada anak RA sangat dominan sehingga pembelajaran melalui tari sangat cocok untuk mengoptimalkan perkembangan gerak/motorik anak (Ria Oku palint, 2014).

Kreativitas berasal dari kata kreatif. Dalam Kamus Besar Bahasa Indonesia, kreatif berarti memiliki daya cipta, memiliki kemampuan untuk menciptakan. Jadi, kreativitas adalah suatu kondisi, sikap, atau keadaan yang sangat khusus sifatnya dan hampir tidak mungkin dirumuskan secara tuntas.

$\begin{array}{ccr}\text { Kreativitas } & \text { dapat } & \text { didefinisikan } \\ \text { dalam beraneka ragam } & \text { pernyataan } \\ \text { tergantung siapa dan } & \text { bagaimana }\end{array}$ menyorotinya. Istilah kreativitas dalam kehidupan sehari-hari selalu dikaitkan dengan prestasi yang istimewa dalam menciptakan sesuatu yang baru, menemukan cara-cara pemecahan masalah yang tidak dapat ditemukan oleh kebanyakan orang, ide-ide baru dan melihat adanya berbagai kemungkinan (Riza Kustiani, 2019).

Secara umum karakteristik dari suatu bentuk kreativitas tampak dalam

1 Ria Oku Palint. 2014. Skripsi : Peningkatan Kreativitas Anak dalam Pembelajaran Seni Tari Melalui Strategi Belajar Sambil Bermain di TK ABA Karangmalang. Program Studi Pendidikan Seni. Fakultas Bahasa dan Seni. Universitas Negeri Yogyakarta. hal 2. proses berpikir saat seseorang memecahkan masalah. Adapun proses berpikir kreatif muncul karena adanya perilaku kreatif. Lima perilaku kreatif tersebut yakni kelancaran (fluency), kelenturan (flexibility), keaslian (originality), elaborasi (elaboration) dan kepekaan (sensitivity). (Ria Oku Palint, 2014).

Ada 24 ciri pribadi kreatif yaitu sebagai berikut: (a) terbuka terhadap pengalaman baru, (b) fleksibel dalam berpikir dan merespons, (c) bebas dalam menyatakan pendapat dan perasaan, (d) menghargai fantasi, (e) tertarik pada kegiatan kreatif, (f) mempunyai pendapat sendiri dan tidak terpengaruh oleh orang lain, (g) mempunyai rasa ingin tahu yang besar, (h) toleran terhadap perbedaan pendapat dan situasi yang tidak pasti, (i) berani mengambil risiko yang diperhitungkan, (j) percaya diri dan mandiri, (k) memiliki tanggung jawab dan komitmen kepada tugas, (l) tekun dan tidak mudah bosan, (m) tidak kehabisan akal dalam pemecahan masalah, (n) kaya akan inisiatif, (o) peka terhadap situasi lingkungan, (p) lebih berorientasi ke masa kini dan masa depan daripada masa lalu, (q) memiliki citra diri dan stabilitas emosi yang baik, (r) tertarik kepada hal-hl yang abstrak, kompleks, holistik, dan mengandung teka teki, (s) memilii gagasan yang orisinal, (t) mempunyai minat yang luas, (u) menggunakan waktu luang untuk kegiatan yang bermanfaat dan konstruktif bagi pengembangan diri, (v) kritis terhadap pendapat orang lain, (w) senang mengajukan pertanyaan yang baik, (x) memiliki kesadaran etika-moral dan estetik yang tinggi (Rachmawati dan Kurniati, 2010).

Seni adalah ungkapan ekpresi pikiran dan imajinasi manusia dalam bentuk nyata. Wujud nyata dari seni itu sendiri beragam dan tidak terhitung jumlahnya. Itu sebabnya banyak orang menjadi berbeda pendapat ketika menilai 
keindahan suatu seni. Seni tari menggunakan media tubuh manusia sebagai alat berekspresi. Dalam melakukan gerak tari, tubuh harus mempunyai kompetensi yang lebih dari gerak lainnya (Nurliza, 2018).

Seni Tari Jaipong merupakan fenomena menarik dan penting dalam perkembanagn tari Sunda di masyarakat, ari kreasi baru yang tumbuh di Jawa Barat. Jaipong terlahir dari hasil kreativitas Gugum Gumbira pada pertengahan tahun 1970-an (Non Dwishiera C.A, 2013)

Belajar merupakan suatu proses, suatu kegiatan dan bukan suatu hasil. Anak usia dini pada umumnya dalam rentang usia yang aktif sehingga anak senang melakukan kegiatan yang menyenangkan. Sedangkan Suratno berpandangan bahwa bermain sesuai kodratnya dilihat dari kematangan psikologis, anak usia prasekolah belum siap untuk memasuki dunia belajar seperti halnya anak sekolah pada umumnya. Kegiatan utamanya adalah bermain dan segala aktivitas yang memberikan kesenangan bagi anak. Melalui strategi belajar sambil bermain maka anak dapat mempelajari banyak hal namun tidak kehilangan masa kanak-kanak untuk bermain (Ria Oku Palint, 2014).

\section{METODE}

Jenis penelitian ini adalah Penelitian Studi Literatur. Studi literatur dilakukan dengan cara mempelajari dan mengkaji buku-buku yang ada hubungannya dengan masalah yang diteliti untuk memperoleh bahan-bahan atau sumber informasi tentang masalah yang diteliti. Teknik pengumpulan data yang digunakan yaitu sumber data primer dan sumber data sekunder. Data primer penelitian ini adalah menggunakan data dari jurnal dan skripsi terdahulu, sedangkan data sekundernya adalah dari buku-buku yang sesuai dengan pembelajaran contextual teaching and learning dan pemahaman konsep. Teknik analisis data yang digunakan dalam penelitian dengan model dari (Miles dan Huberman) yang terdiri dari tiga tahap, antara lain reduksi data, penyajian data dan penarikan kesimpulan/verifikasi. Teknik pengujian keabsahan data penelitian ini menggunakan trigulasi data yaitu trigulasi sumber, trigulasi teknik dan trigulasi waktu.

\section{HASIL DAN PEMBAHASAN}

\section{HASIL}

Penelitian ini dilakukan dengan studi literatur. Teknik Pengumpulan datanya yaitu data primer dari peneliti berjumlah 5 penelitian baik dari skripsi terdahulu dan jurnal Ilmiah (jurnal internasional), sedangkan data sekunder berjumlah 3 buku.

Penelitan data primer adalah :

1. Skripsi, penelitian yang dilakukan oleh :

a. Ria Oku Palint pada tahun 2014. Dengan judul penelitian : Peningkatan Kreativitas Anak dalam Pembelajaran Seni Tari Melalui Strategi Belajar Sambil Bermain di TK ABA Karangmalang. Progam Studi Pendidikan Seni Tari Fakultas Bahasa dan Seni. Universitas Negeri Yogyakarta 2014. Hasil Peneliannya adalah bahwa kreativitas anak dapat ditingkatkan setelah diberi tindakan melalui strategi belajar sambil bermain yang diterapkan pada pembelajaran seni tari. Hasil observasi sebelum tindakan menunjukkan bahwa skor kreativitas rata-rata yang diperoleh anak adalah 57,9. Ada dua aspek kreativitas yang belum berkembang yaitu orisinalitas dan elaborasi. Pada siklus I skor kreativitas ratarata meningkat menjadi 85,83 dan semua aspek kreativitas telah berkembang namun ada dua aspek yang perkembangannya belum 
maksimal, yaitu fleksibilitas dan elaborasi. Pada siklus II skor kreativitas rata-rata meningkat menjadi 96,66 dan semua aspek kreativitas telah berkembang maksimal. Implikasi dari penelitian ini adalah bahwa guru diseyogyakan menerapkan strategi belajar sambil bermain untuk meningkatkan kreativitas anak dalam pembelajaran seni tari.

b. Riza Kustiani pada tahun 2019. Dengan Judul Penelitian : Meningkatkan Kreativitas Anak Melalui Bermain dan Berkarya Dari Bentuk Geometri Kelompok B di RA Nurussibyan Randu Garut Tugu Semarang Tahun Ajaran 2017/2018. Hasil Penelitiannya adalah bahwa kreativitas anak meningkat setelah dilaksanakannya tindakan bermain dan berkarya dari bentuk geometri . meningkatnya kreativitas anak dapat dilihat dari hasil observasi yang telah dilakukan pada Pra Siklus, Siklus I, dan Siklus II. Sebelum dilakukan tindakan 2 anak atau 13,33\% menunjukkan kreativitas dengan kriteria tinggi, 0 anak atau $0 \%$ menunjukkan kriteria cukup, 5 anak atau 33,34\% menunjukkan kriteria kurang, dan 8 anak atau $53,33 \%$ menunjukkan kriteria rendah. Kemudian pada Siklus I 7 anak atau $46,67 \%$ menunjukkan kriteria tinggi, 4 anak atau 26,67\% menunjukkan kriteria cukup, 2 anak atau 13,33\% menunjukkan kriteria kurang, dan 2 anak atau $13,33 \%$ menunjukkan kriteria rendah. Hasil kreativitas anak kelompok B RA Nurussibyan meningkat dengan signifikan.

c. Miskawati pada tahun 2017. Dengan Judul Penelitian : Upaya Meningkatkan Kreativitas Anak dalam Pembelajaran Seni Tari
Melalui Strategi Belajar Sambil Bermain di TK Islam Sa'adatul Khidmah Tahun Pelajaran 2016/2017. Haisl penelitiannya adalah bahwa kreativitas anak dapat ditingkatkan setelah diberi tindakan melalui strategi belajar sambil bermain yang diterapkan pada pembelajaran seni tari. Hasil observasi sebelum tindakan menunjukkan bahwa skor kreativitas rata-rata yang diperoleh anak adalah 57,9. Ada dua aspek kreativitas yang belum berkembang yaitu orisinalitas dan elaborasi. Pada siklus I skor kreativitas ratarata meningkat menjadi 85,83 dan semua aspek kreativitas telah berkembang namun ada dua aspek yang perkembangannya belum maksimal, yaitu fleksibilitas dan elaborasi. Pada siklus II skor kreativitas rata-rata meningkat menjadi 96,66 dan semua aspek kreativitas telah berkembang maksimal.

d. Yustiana Patrich Rosalia, Slamet Subiyantoro, Margana pada tahun 2019. Dengan Judul Penelitian :"Cundrik Asmarantaka" Dance Learning as a Formation of Children's Personality Based on Local Wisdom at Ande-Ande Lumut Kediri Art Studio". Art Education. Graduate Program. Hasil Penelitiannya adalah bahwa pembelajaran karya tari Cundrik Asmarantaka di Sanggar Seni Ande-ande Lumut mampu mengarahkan dan mencetak kepribadian anak yang bertanggung jawab, percaya diri dalam menjaga dan menjaga nilai-nilai kearifan lokal Kediri. Keberadaan karya tari dalam pembelajaran merupakan cerminan generasi muda dalam kondisi saat ini untuk mengenal dan menanamkan nilai-nilai sejarah, pendidikan, keteladanan, 
kepahlawanan dan akhlak sebagai pengembangan diri untuk dapat menjalani perjuangan hidup dengan kebenaran dan kejujuran melalui kepribadian mereka.

e. Miriam Giguere (Jurnal Internasional) pada tahun 2011. Dengan Judul Penelitian : International Journal of Education \& the Arts : Social Influences on the Creative Process An Examination of Children's Creativity and Learning in Dance. Drexel University, USA. Hasil penelitiannya adalah bahwa Penelitian ini bertujuan untuk (1) mengidentifikasi elemen penting dari lingkungan kelas, yang membantu produktivitas dan aktivitas kognitif siswa; dan (2) melihat bagaimana bekerja sebagai kelompok sebaya mempengaruhi proses kreatif peserta.

2. Penelitian data Sekunder

a. Munandar Utami (2012).

Pengembangan Kreativitas Anak Berbakat. Jakarta : Reneka Cipta.

b. Novi Mulyani 2017. Pengembangan Seni Anak Usia Dini. Jakarta : PT. Remaja Rosdakarya.

c. Widia Pekerti. 2018. Metode Pengembangan Seni. Universitas Terbuka.

\section{PEMBAHASAN PENELITIAN}

Pembahasan dari buku tentang kreativitas anak dalam pembelajaran seni tari Jaipong mealui strategi belajar sambil bermain adalah dibahas salam buku Novi Mulyani bahwa sebagai berikut :

Seni tari adalah salah satu jenis seni atau kesenian yang diajarkan di sekolah. Pendidikan seni tari di lembaga PAUD, pada umumnya menjadi kegiatan ekstrakulikuler. Walaupun bersifat kegiatan ekstra, tetapi seni tari seolah menjadi menu wajib bagi anak-anak untuk mengikutinya. Pengertian seni tari semuanya bermuara pada "gerak" dan "ritme". Nilai-nilai keindahan tari tersebut terletak pada empat hal, yaitu wiraga, wirama, wirasa dan harmoni.

Tari yang berbahan baku gerak, mempunyai elemen atau unsur-unsur pokoknya, yaitu tenaga, ruang dan waktu. Aspek dari tenaga yaitu adanya intensitas, aksen atau tekanan, dan kualitas. Aspek ruang dibedakan menjadi dua macam, yaitu ruang yang diciptakan oleh penari dan ruang pentas atau tempat penari melakukan gerak.Sedangkan, aspek waktu faktor-faktornya dibedakan menjadi dua yaitu tempo dan ritme dalam gerak tari.

Seni tari sebagai bagian dari pendidikan seni yang berfungsi untuk memperhalus budi pekerti manusia, sehingga sebagai warga masyarakat kelak, disamping kecerdasan dan pengetahuan yang diperoleh di bangku sekolah, mereka ditempa pula kepribadian dan sikapnya untuk dapat merasakan dan menghargai nilai-nilai keindahan dari keseluruhan kehidupannya. Hal ini karena pembelajaran seni tari sejatinya tidak hanya bertujuan untuk mengembangkan seni itu sendiri, tetapi juga untuk mengembangkan potensi dan dimensi lain yang dimiliki anak. karena dalam pembelajaran tari, dimensi keilmuan mencakup di dalannya. cakupan itu antara lain, berhitung, membaca, bercerita, gerak, nyanyian, serta nilai-nilai kehidupan seperti kedisiplinan, ketekunan, kerja sama dalam kelompok dan lainnya.

Seni tari dan kreativitas erat sekali hubungannya. Usia yang paling tepat dalam kehidupan manusia untuk merangsang kreativitas adalah ketika anak usia dini. Dengan demikian adalah suatu 
keharuasan untuk merangsang kreativitas anak-anak sebagai bekal untuk kehidupannya kelak.

Dalam Pembelajaran seni tari, anak dilatih dalam meningkatkan kreativitasnya. Tentu saja, karena hal ini konteksnya adalah tari, maka konsep kreativitas anak lebih ditekankan kepada pembentukan atau penemuan gerakan-gerakan baru dan kreatif, yang pada akhirnya dijadikan untuk materi seni tari.

Perlu dipahami bersama, bahwa setiap anak itu kreatif. Tugas sebagai pendidik, baik itu orang tua maupun guru adalah bagaimana merangsang kreativitasnya yaitu dengan memberikan bimbingan atau arahan dalam menciptakan gerak tari sesuai dengan pengetahuan dan pengalaman anak, serta dengan mendorong anak agar berani mengungkapkan ide-ide kreatifnya. Proses menemukan dan mengungkapkan ide-ide itulah yang disebut kreativitas anak dalam seni tari (Novi Mulyani, 2017).

\section{DAFTAR PUSTAKA}

Diantama, Suarifqi. (2018). Metode Penelitian Pendidikan. Bandung: Pustaka Rahmat.

Maulidya Ulfah, Suyadidan. 2015. Konsep Dasar PAUD. Bandung: Remaja Rosdakarya.

Mulyani, Novi. 2017. Pengembangan Seni Anak Usia Dini. Jakarta : PT. Remaja Rosdakarya.

Munandar Utami. (2012). Pengembangan Kreativitas Anak Berbakat. Jakarta : Reneka Cipta.

Sugiyono. 2011. Metode Penelitian Kombinasi (Mixed Method). Bandung: Alfabeta.
Supriatna, Atang dan Rama Sastra Negara. 2010. Pendidikan Seni Tari untuk SMP/MTs. Jakarta: CV. Ricardo.

Susanto, Ahmad. (2011). Perkembangan Anak Usia Dini. Jakarta: Kencana Prenada Media. hal 122.

Suriapna. 2016. Teori Belajar Pembelajaran di Sekolah Dasar. Jakarta: Kencana.

Bambang. 2017. Pendidikan Anak Usia Dini. Jakarta: Bumi Aksara.

Rachmawati, Yeni dan Euis Kurniati. 2010. Strategi Pengembangan Kreativitas pada Anak Usia Dini Taman Kanak-Kanak Edisi Pertama. Jakarta: Kencana.

Tumurang, Hetty. 2016. Pembelajaran Kreativitas Seni Anak Sekolah Dasar. Jakarta: Departemen Pendidikan Nasional.

Agustini, Reni. 2019. Meningkatkan Kemampuan Menari Anak Usia Dini Melalui Kegiatan Tari Kreasi "Yamko Rambe Yamko" di Kelompok B PAUD An-Nazwa Kecamatan Cikeusal Tahun Pelajaran 2018-2019. Program Studi Pendidikan Guru Pendidikan Anak Usia Dini. STKIP Banten.

Eko. Scribd: Standar Tingkat Pencapaian Perkembangan Anak Usia 4-6 Tahun TKKTegaljaya. https://www.scribd.com/document/4 00726456/SETANDAR-1

Kustiani, Riza. 2019. Skripsi : Meningkatkan Kreativitas Anak Melalui Bermain dan Berkarya dari Bentuk Geometri Kelompok B di Ra Nurussibyan Randu Garut Tugu Semarang Tahun Ajaran 2017/2018. Fakultas Tarbiyah dan 
keguruan. Universitas Islam Negeri Walisongo Semarang.

Miskawati. 2017. Jurnal Ilmiah Dikdaya : Upaya Meningkatkan Kreativitas Anak dalam Pembelajaran Seni Tari Melalui Strategi Belajar Sambil Bermain di TK Islam Sa'adatul Khidmah Tahun Pelajaran 2016/2017.

Munawaroh, Hidayatu. 2017. Jurnal : Implementasi Pembelajaran Tari Dalam Mengembangkan Aspek Perkembangan Anak Usia Dini. Program Studi Pendidikan Islam Anak Usia Dini (PIAUD). Universitas Sains Al-Qur'an.I

Non Dwishiera C.A, 2013 Tari Jaipong Karya Rumingkang Sebagai Media Industri Kreatif Berbasis Seni Tradisi. Universitas Pendidikan Indonesia.

Nurliza. 2018. Skripsi: Meningkatkan Kreativitas Anak Usia Dini 5-6 Tahun Kelompok B Melalui Seni Gerak dan Tari Di TKIT Nurul Ilmi Percut Sei Tuan Tahun Ajaran 2017/2018. Jurusan Pendidikan Islam Anak Usia Dini. Fakultas Tarbiyah dan Keguruan. Universitas Islam Negeri Sumatera Utara Medan.

Oku Palint, Ria. 2014. Skripsi : Peningkatan Kreativitas Anak dalam Pembelajaran Seni Tari Melalui Strategi Belajar Sambil Bermain di TK ABA Karangmalang. Program Studi Pendidikan Seni. Fakultas Bahasa dan Seni. Universitas Negeri Yogyakarta.

Patriani Yakub, Yenni. 2010. Mengenal Tarian Tunggal Nusantara. Jakarta Timur : Horizon.

Patrich Rosalia, Yustiana. Slamet Subiyantoro, Msrgana. 2019.
Internasional Conference on Arts Language and Culture : "Cundrik Asmarantaka" Dance Learning as a Formation of Children's Personality Based on Local Wisdom at AndeAnde Lumut Kediri Art Studio. Sebelas Maret University. Surakarta Indonesia

Ria oku palint. 2014. Skripsi : Peningkatan Kreativitas Anak dalam Pembelajaran Seni Tari Melalui Strategi Belajar Sambil Bermain di TK ABA Karangmalang. Program Studi Pendidikan Seni. Fakultas Bahasa dan Seni. Universitas Negeri Yogyakarta.

Sugiyono. 2011. Metode Penelitian Kuantitatif Kualitatif Dan $R \& D$. Bandung: Alfabeta.

Sutini, Ai. Jurnal : Pembelajaran Tari bagi Anak Usia Dini.

Suyadi. 2014. Teori Pembelajaran Anak Usia Dini dalam Kajian Neurosains. Bandung: PT. Remaja Rosdakarya. hal 167.

Universitas

Pasundan.

http://repository.unpas.ac.id/38351/4/BAB \%20II.pdf 